\section{Liberals, conservatives, and conformity}

FRANK SISTRUNK, University of South Florida, Tampa, Fla. 33620, and CHARLES G. HALCOMB, Texas Technological College, Lubbock, Tex. 79401

Patterns of conforming behavior were compared for $S$ s empirically contrasted as conservatives, moderates, or liberals on a politically based Thurstone-type scale. In a split-plot factorial analysis-of-variance design, liberalism-conservatism of the $S$ s and political identification of the influence sources were employed as between-Ss variables, while task difficulty operated as a within-Ss variable. The finding of major interest was that conservatives conformed more than moderates who conformed more than liberals. Further analysis revealed that, in general, conservatives were conformers, liberals were independent, and the conformity of moderates was dependent on the nature of the judgmental task.

Studies of personality variables associated with conforming behavior have suggested consistently that there are stable relationships between conformity and certain personality and motivational factors (e.g., Barron, 1953; Crutchfield, 1955; DiVesta, 1958; Tuddenham, 1958). While the literature certainly does not reveal a "conforming personality," there are indications of meaningful personality correlates of conformity under different specified circumstances (e.g., McDavid \& Sistrunk, 1964). However, additional explorations of particular $S$ factors, operating under specified conditions, are needed to elucidate questions about the personal characteristics of the conformer.

The purpose of the present investigation was to explore the effects of social influence upon persons contrasted on the basis of liberalism-conservatism. A Thurstone-type scale of politically oriented liberalism-conservatism, which had demonstrated predictive validity in a genuine political situation (Wright \& Hicks, 1966), was chosen for preselection of Ss into contrasted groups. The identification of the source of influence on a political basis, as Republican or Democratic students, was manipulated as a second independent variable. Thus, comparisons were made of the conforming behavior of conservative, moderate, and liberal students.

\section{SUBJECTS}

One hundred university students in Texas and Florida were administered the
Liberalism-Conservatism Scale (L-C), a Thurstone-type scale constructed and validated by Wright \& Hicks (1966). The students were also asked to indicate whether they considered themselves to be, in general, conservative or liberal. The scores on the L-C measure ranged from 3.87 to 10.07 . On the self-perception question, $44 \%$ answered conservative and $56 \%$ liberal. From this population, 48 Ss were selected for final study based on their empirical identification within contrasted groups of "conservatives," "moderates," and "liberals." The criteria employed for the conservative group were a high score on the L-C scale $(8.75-10.07)$ and self-identification as conservative. The criteria for the liberal group were a low score on the L-C measure (3.87-5.61) and self-identification as liberal. The moderate group was composed of Ss who scored in the middle range on the L-C measure (6.65.7.98), irrespective of self-identification. Actually, the self-descriptions of the Ss in the moderate group were split evenly between conservative and liberal.

\section{PROCEDURE}

Observations of conforming behavior were made within the context of a series of judgmental tasks disguised as a group-administered paper-and-pencil "synonyms" test. Each of 70 items presented a key word, with four alternative multiple choices presented to the right. $S$ was instructed to indicate which of the four alternatives represented the closest synonym for the key word. Social influence was exerted, not in the form of reports from the people physically present, but through penciled markes on the test booklet beside predesignated items. Such marks appeared beside 25 of the test items in irregular sequence, and were attributed by $\mathbf{E}$ to previous users of the test booklets. In giving instructions to the Ss, E informally commented that he was aware that prior users of the booklets had, despite his instructions, carelessly marked on some of the booklets but that since there had not been time to go through and erase the marks or to prepare new test booklets, $S$ should disregard any such marks he might encounter. The marks varied in form, but represented an attempt to simulate the marks a test-taker might place beside the multiple choices in deciding which answers he would select. This type of procedure had been utilized previously by Coffin (1941), Patel \& Gordon (1960), and Sistrunk \& McDavid (1964). On 20 "critical" items, the marks designated actually incorrect alternatives in order to exert pressure on S's judgment, while on 5 "control" items, the marks appeared beside actually correct choices in order to alleviate suspicion of contrivance.

By variation of conditions, two situational manipulations were achieved: difficulty of the tasks and identification of the sources of influence. Task difficulty: Within the synonyms test, 10 of the critical influence items represented "easy" tasks in that $90 \%$ of a pretest sample from a similar population (Sistrunk \& McDavid, 1964) were able to select the correct synonym. Ten other items represented "difficult" tasks, on which fewer than $25 \%$ of the pretest Ss were able to identify the correct synonym. Thus, the task difficulty variable operated within Ss, with each $S$ receiving both levels of task treatment. Influence source: Half of the Ss were informed by statements embedded within the instructions that the previous users of the test booklets (the presumed source of the penciled marks) were a group of active Republican students; the remaining half were informed that the previous test-takers were active Democratic students. This manipulation afforded a characterization of the source of influence that was relevant to the political, liberalism-conservatism dimension on which the Ss had been preselected.

\section{RESULTS}

The data were submitted to a split plot factorial (SPF 3,2.2) analysis of variance (Kirk, 1968) with liberalism-conservatism (L) of the Ss and nature of the influence source (I) employed as between-Ss variables, and with task difficulty operating as a within-Ss variable. Duncan's new multiple-range test (Edwards, 1960) was selected for multiple comparisons among means following significant $F$ ratios.

The main effects of liberalism (L) and task difficulty (T) were statistically significant $(\mathrm{p}<.001)$, but influence source (I) was not $(p>.05)$. Conservative $\mathrm{Ss}$ conformed more than did moderates $(p<.05)$ and moderates conformed more than did liberals $(p<.001)$. As usually expected, there was greater yielding to the information from others on the difficult tasks than on the easy tasks $(p<.001)$, but there were no differential effects of the influence source on the Ss. The $\mathrm{T}$ by $\mathrm{L}$ interaction was significant $(\mathrm{p}<.05)$ and elaborated the main effect of increasing conformity from liberal to moderate to conservative.

\section{DISCUSSION}

The finding of major interest was the relative conforming of the $\mathrm{Ss}$ who had been measured as liberal (11\%), moderate $(33 \%)$, and conservative $(47 \%)$. This was a strong 


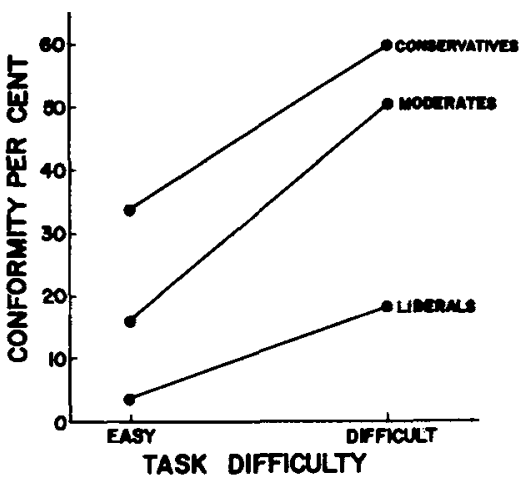

Fig. 1. Liberalism-Conservatism by Task Difficulty interaction.

effect $(p<.001)$ as subject/personality variables typically operate in this kind of research, and the effect held across the nature of the source of influence. Even though the L-C scale was developed by Wright and Hicks on a political basis, the extremely conservative Ss yielded to both Democratic and Republican sources and those extremely liberal yielded to neither.

The statistically significant $T$ by $L$ interaction further elaborated this tendency of conservatives to conform more than liberals. Notice the trend displayed in Fig. 1 of the relative yielding of the three subject groups. The significant main effect of $\mathbf{L}$ showed the same trend of relative conformity as is portrayed on the easy tasks. The trend was essentially repeated on the difficult tasks, with the exception of the relatively higher yielding of the moderates on these difficult tasks. The conformity of the moderates was high enough to be not significantly different from the conformity of the conservatives, even though the groups had differed at the .01 level on easy tasks. Recall the nature of the easy and the difficult tasks. The easy tasks were constructed to be quite easy, with $90 \%$ of pretest Ss answering them correctly, and the difficult tasks were constructed to be quite difficult and were answered correctly by less than $25 \%$ of the pretest Ss. Notice again in Fig. 1 that the conservatives actually conformed more on these easy tasks (33\%) than the liberals did on the difficult tasks $(19 \%)(p<.01)$. This was a rather remarkable finding in light of the contrasted difficulty of the task items. It appeared that while the extreme liberals were conforming very little, even in the face of difficult synonyms, the extreme conservatives were conforming rather indiscriminately in terms of the task. On the other hand, the behavior of the moderates was more complex. They were certainly susceptible to social influence in that they conformed considerably (33\%), but they appeared to perform in a discriminating informational manner with low yielding on easy tasks $(16 \%)$ but high yielding on difficult tasks $(51 \%)$ when they needed extra information.

In summary, within the context of this behavioral situation, the conservatives were conformers, the liberals were independent, and the moderates responded differentially to influence, depending upon the nature of the task confronting them.

\section{REFERENCES}

BARRON, F. Some personality correlates of independence of judgment. Journal of Personality, 1953, 21, 287-297.

COFFIN, T. E. Some conditions of suggestibility and susceptibility: $A$ study of certain attitudinal and situational factors influencing the process of suggestion. Psychological Monographs, 1941, 53, No. 241.

CRUTCHFIELD, R. S. Conformity and character. American Psychologist, 1955, 10, 191-198.

DIVESTA, F. J. Susceptibility to pressures toward uniformity of behavior in social situations: A study of task, motivational, and personal factors in conformity behavior. ASTIA No. 158-291, 1958, AFOSR TR No. 58-70, Washington, D.C.

EDWARDS, A. L. Experimental design in psychological research. New York: Rinehart, 1960.

KIRK, R. E. Experimental design: Procedures for the behavioral sciences. Belmont, Calif.: Brooks-Cole, 1968.

McDAVID, J. W., \& SISTRUNK, F. Personality correlates of two kinds of conforming behavior. Journal of Personality, 1964, 32, $420-435$.

PATEL, A. S., \& GORDON, J. E. Some personal and situational determinants of yielding to influence. Journal of Abnormal \& Social Psychology, 1960, 61, 411-413.

SISTRUNK, F., \& McDAVID, J. W. Conforming behavior as a function of the interaction of situational variables and needs for affiliation and achievement. Technical Report No.6, University of Miami, 1964, Contract Nonr-840(22), NR 177-303, Office of Naval Research.

TUDDENHAM, R. D. Some correlates of yielding to a distorted group norm. Technical Report No. 8, University of California, Berkeley, 1958, Contract NR 170-159, Office of Naval Research.

WRIGHT, J. H., \& HICKS, J. M. Construction and validation of a Thurstone scale of liberalism-conservatism. Joumal of Applied Psychology, 1966, 50, 9-12. 